\title{
Research on the Impact of Green Finance and Fintech in Smart City
}

\author{
Zheng He, ${ }^{1}$ Zhengkai Liu, ${ }^{2}$ Hui Wu $\mathbb{D},{ }^{3}$ Xiaomin Gu ${ }^{(B)}{ }^{3}$ Yuanjun Zhao, ${ }^{4}$ \\ and Xiaoguang $\mathbf{Y u e}^{5}$ \\ ${ }^{1}$ School of Economics \& Management, Shanghai Maritime University, Shanghai 201306, China \\ ${ }^{2}$ International College, Renmin University of China, Beijing 100872, China \\ ${ }^{3}$ School of Financial Technology, Shanghai Lixin University of Accounting and Finance, Shanghai 201209, China \\ ${ }^{4}$ School of Business Administration, Shanghai Lixin University of Accounting and Finance, Shanghai 201209, China \\ ${ }^{5}$ Department of Computer Science and Engineering, School of Sciences, European University Cyprus, 1516 Nicosia, Cyprus \\ Correspondence should be addressed to Hui Wu; wuhui@lixin.edu.cn
}

Received 15 October 2020; Revised 25 November 2020; Accepted 30 November 2020; Published 8 December 2020

Academic Editor: Zhihan Lv

Copyright (c) 2020 Zheng He et al. This is an open access article distributed under the Creative Commons Attribution License, which permits unrestricted use, distribution, and reproduction in any medium, provided the original work is properly cited.

\begin{abstract}
The green development level reflected in the green finance index and the evaluation of the degree of green development in smart cities have important practical effects on economic transformation. For promoting the transformation and upgrading of finance, we select 2013-2019 data and construct a distributed lag model to analyse the important role played by green finance and financial technology in the construction of smart cities. In the paper, we find green finance promotes the construction of smart cities, and only it will not appear until nine months late. Financial technology has an opposite impact on the construction of smart cities, this is mainly because the research and marketization of financial technology are higher, and the cost is also higher. This influence will appear in the next 14 months.
\end{abstract}

\section{Introduction}

The severe destruction of the global ecological environment is accompanied by the rapid development of the global economy. Therefore, many countries attach great importance to achieving "green growth" of their economies while vigorously developing their economies. The green upgrading of traditional industries and the growth of strategic green emerging industries require the effective empowerment of the financial sector, and the supply of green physical industries by the financial sector is a significant manifestation of green finance. Finance is the core of the modern economy. If we want to promote the economy, we must develop high-quality finance and use finance to avoid economic uncertainty. For China's current development, green finance is the way to circumvent this uncertainty and is an important driving force for promoting supply-side structural reforms. The green development level reflected in the green finance index and the evaluation of the degree of green development in a region have important practical effects on economic transformation, reducing investment risks, and helping traditional enterprises improve their sustainable development capabilities.

Fintech refers to financial innovation brought by new technologies. It can create new business models, applications, processes, or products, which has a significant impact on the way financial markets, financial institutions, or financial services are provided. The business scenarios where technology and finance are combined mainly include financial supervision, payment settlement, financing products and services, insurance, smart investment advisory, and energy trading. The underlying technologies include artificial intelligence, blockchain, cloud computing, big data, and the Internet of Things. In the global sustainable financial development process, financial institutions and fintech companies in various countries in the world, especially in Europe, the United States, and China, have tried to integrate fintech and financial technology by actively using blockchain, artificial intelligence, big data, and the Internet of Things, combining green finance to carry out green finance technology exploration and practice. 
Smart cities are inseparable from the joint construction of all sectors of society. In the financial field, the close cooperation of the banking industry is required. With China's rapid economic and social development, the production and life of urban residents can no longer be separated from financial activities, and letting the development of financial technology benefit each inhabitant is an important part of the construction of a smart city. Correspondingly, in the era of the mobile Internet, technological means have fundamentally restructured people's behaviour habits, and banks must also change the financial services they provide in time. The construction of smart cities has been closely integrated with the development of banks. The People's Bank of China has repeatedly called on commercial banks to continuously strengthen the innovative use of financial technology to inject new vitality into urban construction. Local governments have also actively sought to cooperate with banks. The cooperation between the government and the bank has made great progress in various fields such as people's livelihood, education, and public utilities.

The specific contributions of this paper include the following:

(1) A literature survey about various existing distributed lag models and analysis of their advantages and disadvantages.

(2) An effective distributed lag model for green finance and fintech in the smart city is proposed.

(3) It can be seen that there is a relatively obvious correlation between the two in the seventh lag and the twelfth lag, indicating that the two models are affected to some extent by other common variables.

The rest of this paper is organized as follows: Section 2 discusses related work, followed by the empirical analysis in Section 3. Estimation of parameters for smart cities by green finance is discussed in Section 4. Section 5 shows the discussion of the distributed lag model empirical results. Section 6 concludes the paper with a summary and future research directions.

\section{Related Work}

In foreign studies, green finance is also known as environmental finance, which is a definition of financial greening derived from environmental issues and the need to promote sustainable development. From an economic point of view, environmental issues have significant externality characteristics, which can produce positive externalities and negative externalities. Related theories include externalities, Coase's theorem, government intervention, and Pareto improvement. The development of green finance has a driving role in environmental protection, energy conservation and emission reduction, and sustainable development, so it will bring good external effects. However, good external effects directly lead to higher costs for financial institutions to implement green finance, which ultimately leads to a lack of incentives and insufficient effective supply for the private sector to implement green finance, and it is almost impossible to achieve Pareto optimal asset allocation.

Green finance is to support sustainable development, that is, sustainable finance; it is a path of innovation in finance in environmental protection, and it is a link between the financial industry and the environmental industry [1]. Green finance is a financial tool based on market research to improve environmental quality and transfer environmental risks. As a method and means to promote sustainable development, green financial services have become the mainstream trend of financial development. Although the concept of green finance is widely recognized, it lacks a complete evaluation system, which makes it slow to develop. Some scholars have established evaluation index systems to analyse the performance problems of bank green service channels in operations and use real data from well-known banks. Based on the evaluation and analysis of their sustainable development concept and specific practices, they constructed a five-dimensional index evaluation system. Through a series of studies, it was found that although the cost of implementing the "equatorial principle" is higher, the credit risk generated by loans is lower [2-4].

The international understanding of green finance can be roughly divided into two categories: the first category regards green finance as investment and financing activities that improve the environment, that is, green investment. The starting point of this understanding is to "make up the investment gap" [2]. Another type of understanding directly incorporates environmental factors into the field of financial investment, including changes in environmental costs, changes in risk coefficients, and changes in returns and returns caused by engaging in business. It is believed that the development of green finance is based on the mutual constraints between finance and the environment [5]. For example, green finance incorporates environmental factors into financial services, such as bank investment or reception decisions, postloan monitoring, and participation in environmental assessment during risk management [6]. The above two categories are both different and related.

Over time, overseas scholars have also elaborated a series of issues in the development of green finance. Further analysis shows that the return on investment of such funds is longer with the cycle, and the overall investment income is not worse than other mutual funds.

Fintech is a modern concept and so far, no unified definition has been formed. However, in 1993, the term "fintech" appeared in the relevant report of Citibank. Attempts to enable technology to finance have gradually begun, and it has been intensified with the increasing enrichment of Internet financial practices and the continuous upgrading of the transformation of the financial sector. It can be said that fintech has quietly integrated into people's lives before society has realized it. The Financial Stability Board (FSB) believes that fintech refers to technological innovation that can significantly affect financial markets, institutions, and services and is mainly accomplished through innovative business models, application methods, process methods, and product types. 
The definition of fintech has been gradually clarified in continuous research. Most scholars define fintech as a technological solution that can realize the transformation of the financial service industry. They believe that fintech is a new industry that uses technological innovation to improve the quality of financial services. Science and technology are a disruptive emerging financial industry. It mainly uses digital and information technology to achieve innovation in the existing economic model $[7,8]$. In summary, fintech refers to financial innovation driven by technological innovation. Through the deep integration of finance and technology, big data, blockchain, artificial intelligence, and cloud computing are the main technical support, which has changed financial business processes. And business models challenge traditional financial thinking. Fintech has given impetus to various industries in finance-related fields by expanding the service boundaries of financial institutions and improving service methods while increasing financial efficiency and while minimizing risks [9-11]. However, fintech cannot be simply understood as the superposition of the two. It is more a process of gradual integration and deepening of emerging technologies and financial services to continuously promote the transformation and upgrading of traditional financial services.

The definition of "smart city" comes from the vision of "Smart Earth." IBM released the theme report of "Smart Earth: Next Generation Leadership Agenda" in New York in 2008. The report mentioned "Smart Earth," which actually refers to the full use of IT technology and sensors in various industries to embed in hospitals, power grids, railways, bridges, tunnels, highways, buildings, and other objects in the corners of the world, connect various objects to form the Internet of Things, then integrate the Internet of Things with the Internet, and finally use supercomputers and cloud computing to integrate the Internet of Things.

The construction of a smart city is not a process with clear boundaries, so there is no unified interpretation of its concept. The concept of early smart cities is mainly related to the operational functions, management, and planning efficiency of smart technology solutions in energy, transportation, physical infrastructure, distribution and communication networks, economic development, and service delivery. With the development of smart cities, more and more emphasis is placed on the use of information technology to achieve the purpose of urbanization, and a definition of a focused and operable smart city is gradually given. Invest in social capital, traditional, and modern communications infrastructure to promote sustainable economic growth and high-quality living, and wise management of natural resources. Emphasize the role of information technology. Think of smart cities as transforming productivity, to achieve the prosperity of the city and benefit the people [12-15]. Some scholars have begun to define smart cities from the perspective of the Internet. They believe that smart cities are a complex system containing multiple visions $[16,17]$. Recently, with the development of information technology, more and more foreign scholars have begun to focus on sustainable development incorporating into the concept of smart cities, emphasizing the improvement of environmental issues through technological development.

In addition, scholars have also made related research on smart city assessment. From different perspectives, they built innovative cities, regional green cities, quality of life, digital government, and so forth as evaluation indicators and carried out evaluation work on smart cities in different countries around the world [18] to promote the sustainable development of smart cities. Later, scholars carried out evaluations of smart city performance, proposed models for measuring smart city performance, and conducted empirical research.

Fintech itself is based on "science and technology," its purpose is to promote the transformation and upgrading of finance, and it is an important force to promote the development of green finance [19]. This study explores the impact of finance on the construction of smart cities from an innovation-driven perspective and analyses the important role played by green finance and financial technology in the construction of smart cities.

\section{Empirical Analysis}

3.1. Data Source. The starting year of the time series data selected in this article is 2013 because 2013 is called "the first year of Internet finance." In the study of green finance, fintech, and smart cities, this article selected seven-year data from 2013 to 2019, which can more clearly rely on the latest year's data to understand the specific impact between the three [20]. The data are constructed through an index system. Green finance indicators include seven aspects: green credit, green bonds, green development funds, green insurance, green stocks, green investment, and carbon finance. The city index is constructed from four perspectives: smart technology, smart economy, smart society, and smart environment.

3.2. Model Setting and Identification. Since the independent and explanatory variables involved in this study are time series data, the structure of a commonly used linear regression model is as follows:

$$
Y_{t}=C+\sum_{i=1}^{k} \beta_{i} X_{i t}+\varepsilon_{t},
$$

in which $Y_{t}$ is the time series of the dependent variable, $X_{i t}$ is the time series of the $i$-th independent variable, $\varepsilon_{t}$ is the random disturbance term (disturbance term), and $C$ is the constant term. In order to use the least square method (ordinary least square) for estimation, it is usually assumed that the random perturbation term and independent variable are independent of each other, and the random perturbation term is independent and identically distributed. However, the above model itself and the basic assumptions about the random perturbations have three problems: they ignore the lag effect of the independent variables, cannot handle the autocorrelation of the perturbations, and are misleadingly related [21]. 
In view of the above problems, this article considers the use of the dynamic regression model (dynamic regression) and introduces the lag term in the initial dynamic regression model [22]. According to the different representations of the lag term, there are two kinds of dynamic regression models: Linear Distributed Lag Model (LDL) and Rational Distributed Lag Model (RDL) [23]. Since the actual data has only a limited number of data samples, it is not possible to directly estimate the parameters of the LDL model. So this research uses the RDL model; the specific expression is as follows:

$Y_{t}=C+\frac{\omega(B) B^{b}}{\delta(B)} X_{t}+\varepsilon_{t}=C+\frac{\left(\omega_{0}+\omega_{1} B+\cdots+\omega_{h} B^{h}\right) B^{b}}{1-\delta_{1} B-\delta_{2} B^{2}-\cdots-\delta r B^{r}} X_{t}+\varepsilon_{t}$.

The RDL model can describe more complex changes in impulse response weights through the combination of multiple backshift operators, thereby better fitting the data, in which $B^{b}$ is used to reflect the dead time, that is, the time interval when the independent variable starts to affect the dependent variable; $\delta(B)$ represents the Decay Pattern; and $\omega(B)$ reflects the absence of the impulse response weight.

This article will use the Box-Jenkins dynamic model construction strategy, namely, model identification, parameter estimation, and model diagnosis [24]. When the Box-Jenkins dynamic model construction strategy is officially started, according to the actual operation experience, the following preprocessing tasks will be performed on the original data in order, which will help the subsequent modelling process to proceed smoothly [25].

(1) Perform differential processing on the independent and dependent variable sequences and convert them into stationary sequences $\left\{X_{t}^{\prime}\right\}$ and $\left\{Y_{t}^{\prime}\right\}$.

(2) Prewrite independent variable sequence to obtain the perturbation sequence $\left\{a_{t}\right\}$ of the autoregressive moving average model (hereinafter referred to as ARMA model) of the independent variable sequence, which is a white noise process; its ARMA model is as follows:

$$
a_{t}=C+\frac{\varphi(B)}{\theta(B)} X_{t}^{\prime}
$$

(3) Apply the filter expression obtained in (2) to the dependent variable sequence to obtain another sequence of perturbed terms. The process is as follows:

$$
\beta_{t}=\frac{\varphi(B)}{\theta(B)} Y_{t}^{\prime}
$$

(4) Calculate the cross-correlation function of the sequences $x$ and $y$ (hereinafter abbreviated as CCF), and perform a Ljung-Box population test on the given number of lag terms $k$. If the null hypothesis is rejected, explain the first $k$ lags of the independent variable sequence. At least one of the terms has a significant nonzero correlation with the dependent variable; that is, the independent variable has explanatory power to the dependent variable and should be added to the RDL model.

Firstly, clarify three key parameters in the polynomial ratio form of the impulse response function-the molecular polynomial order $h$, the dead time $b$, and the denominator polynomial order $r$.

Secondly, the ARIMA model expression of the perturbation term is as follows:

$$
\varepsilon_{t}=\frac{\Theta\left(B^{s}\right) \theta(B)}{\Phi\left(B^{s}\right) \varphi(B)} \nabla_{s}^{D} \nabla^{d} a_{t}
$$

in which $a_{t}$ is a normally distributed white noise with a mean of 0 [26].

This paper chooses the linear transfer function method (the LTF method) to complete the entire model identification task. The LTF method requires the establishment of the following free-form distribution lag model (the FFDL model):

$$
Y_{t}=C+v_{0} X_{t}+v_{1} X_{t-1}+\cdots+v_{k} X_{t-k}+\frac{1}{\left(1-\varphi_{s} B^{s}\right)\left(1-\varphi_{1} B\right)} a_{t},
$$

in which $k$ is the number of lag effect terms chosen arbitrarily, generally the values that can be considered are $-5,10$, 15 , and 20 , and $k$ is selected in this paper; for the disturbance term, this paper chooses a low-order autoregressive model (the AR model) to improve the accuracy of impulse response weight estimates. In the presence of seasonal effects, the AR (1) can usually be considered [27].

3.2.1. Model Estimation. After the model recognition task is completed, the following complete model expression can be obtained:

$$
Y_{t}=C+\frac{\omega(B) B^{b}}{\delta(B)} X_{t}+\frac{\Theta\left(B^{s}\right) \theta(B)}{\Phi\left(B^{s}\right) \varphi(B)} \nabla_{s}^{D} \nabla^{d} a_{t} .
$$

3.2.2. Model Diagnosis. Then, perform a maximum natural estimation on (6). It should be noted that both $\left\{X_{t}\right\}$ and $\left\{Y_{t}\right\}$ are sequences that satisfy weak stationary after performing the difference.

3.2.3. Model Comparison. In the process of model identification, there may be multiple candidate models. If multiple models are diagnosed through the model, they will face the problem of choosing between multiple models. There are two commonly used criteria for model comparison: Akaike Information Criterion (AIC) and Bayesian Information Criterion (BIC). The definition formula of AIC is as follows:

$$
\mathrm{AIC}=n \log \left(\widehat{\sigma}^{2}\right)+2 M,
$$


in which $M$ is the number of parameters in the model, $\widehat{\sigma}^{2}$ is the maximum likelihood estimate of the variance of the disturbance term, and $n$ is the amount of data. The definition formula of BIC is as follows:

$$
\mathrm{BIC}=n \log \left(\widehat{\sigma}^{2}\right)+\log (n) M .
$$

From the above definitions, when the amount of data is large $(n>10)$, compared with the AIC criterion, the BIC criterion will impose a larger penalty term on the amount of model parameters. According to the Principle of Parsimony of model selection (Principle of Parsimony), this article will use BIC as the selection criterion-the model with the lowest $\mathrm{BIC}$ value is optimal.

3.2.4. Construct LTF Model and Specify RDL Model Parameters. Specify $K$ as 20 and the perturbation term is approximated by a low-order AR model. Figures 1 and 2 show the changes in the impulse response weights of the two independent variables.

As can be seen from Figure 1, the three key parameters of the green financial independent variables in the RDL model are $b=4, r=0, h=0$. The impulse response weight only slightly exceeds the threshold. As can be seen from Figure 2, the parameters of the RDL model part of the fintech independent variable are $b=14, r=0, h=0+1-1=0$.

Figure 3 shows the residuals SACF and SPACF exhibit white noise characteristics, so the disturbance term partially retains the AR (1) model.

\section{Results}

\subsection{Model Estimation}

4.1.1. Estimation of Parameters for Smart Cities by Green Finance. According to the parameters specified in the model identification stage, the parameters of the RDL model are estimated based on the maximum likelihood estimation method. The results are shown in Table 1.

As can be seen from Table 1, the seasonal part of the disturbance term is not significant, and the molecular polynomial parameter of the independent variable part of $\mathrm{RDL}$ is not significant, so try to specify another set of alternative parameters: $b=9, r=0, h=1+0-1=0$. The estimated results of the revised RDL model are shown in Table 2. It can be seen from this that each parameter passed the significance test.

According to the parameters specified in the model recognition stage, the parameters of the RDL model are estimated based on the maximum likelihood estimation method. The results are shown in Table 3. As can be seen from the figure, the seasonal part of the disturbance term is not significant, and the parameters of the fintech independent variable part are not significant, so an alternative RDL model is selected. The estimated results of the revised RDL model are shown in Table 4, which shows that each parameter passed the significance test.

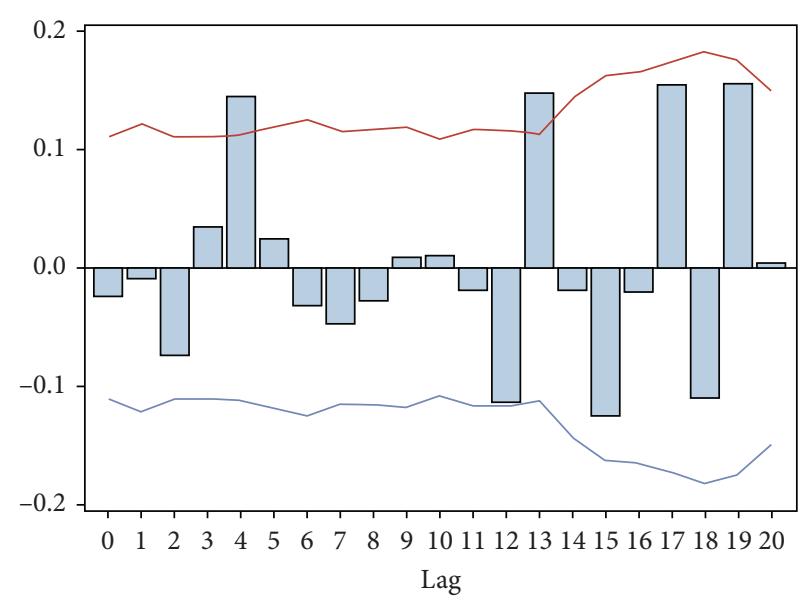

FIGURE 1: Impulse response weights for green finance.

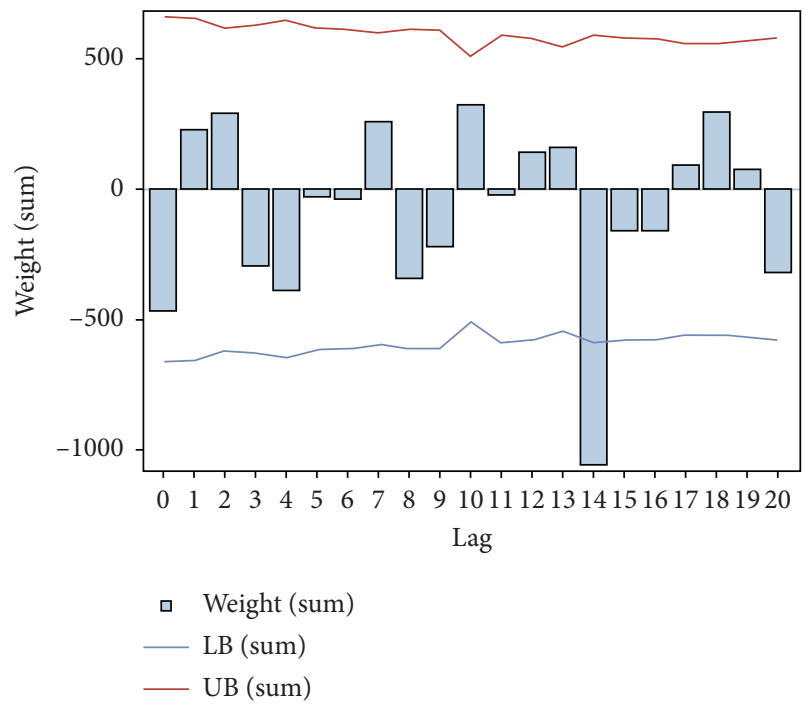

Figure 2: Impulse response weight map of fintech.

4.2. Model Diagnosis and Analysis. The first step is to perform residual diagnosis on the RDL model. As can be seen from Figures 4 and 5, the residuals of the modified RDL model can pass the autocorrelation and normality tests.

The second step is to perform residual diagnosis on the independent variable ARIMA model. The results are shown in Table 5 and Figure 6 . Table 5 shows that each parameter passed the significance test, and it can be seen from Figure 6 that IACF and PACF show that the residuals pass the autocorrelation test, but they are not white noise.

In the third step, a Ljung-Box test is performed on the two residual sequences CCF, and the result is shown in Figure 7. It can be seen that there is a relatively obvious correlation between the two in the seventh lag and the twelfth lag, indicating that the two models are affected to some extent by other common variables.

From the model estimation and diagnosis results, we can know that green finance has a significant positive impact on the construction of smart cities, and this impact will occur after nine months. Fintech has a significant negative impact 


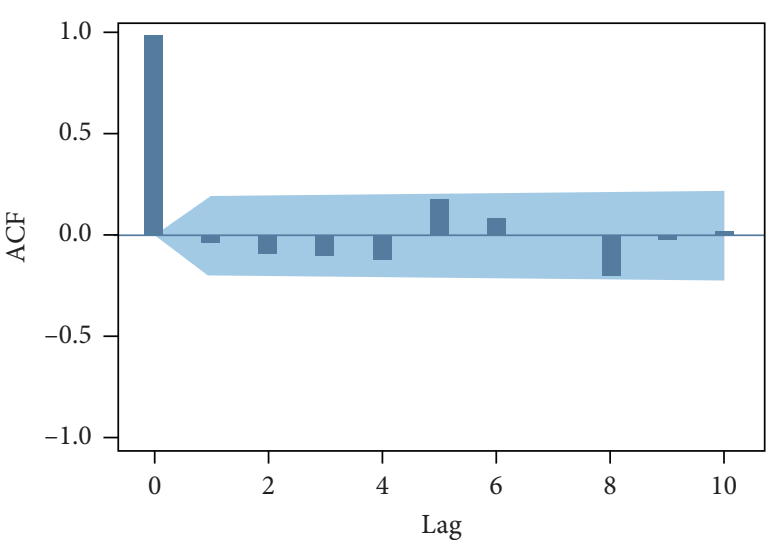

(a)

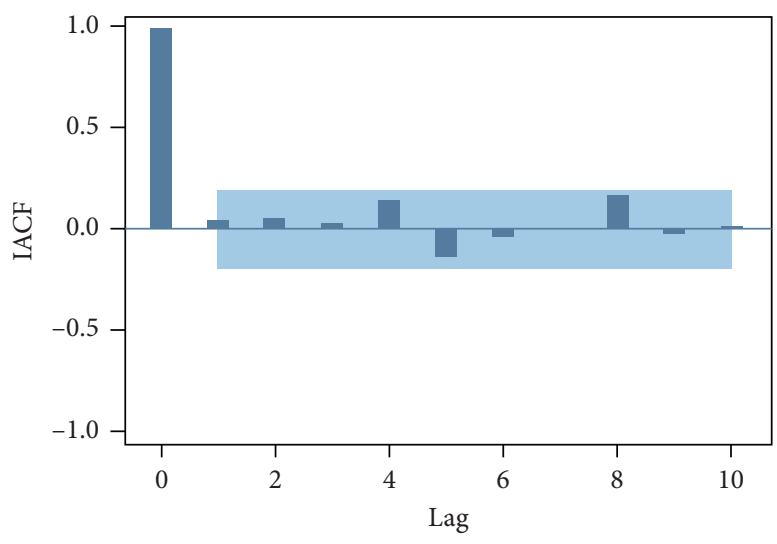

(c)

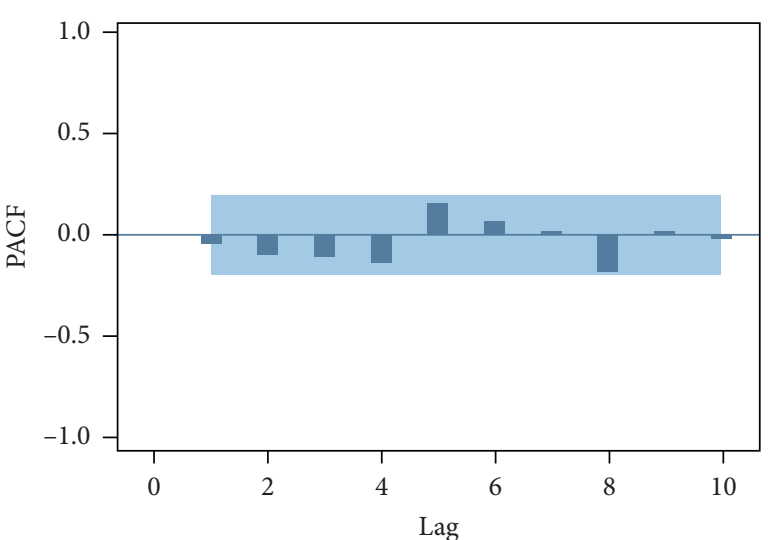

(b)

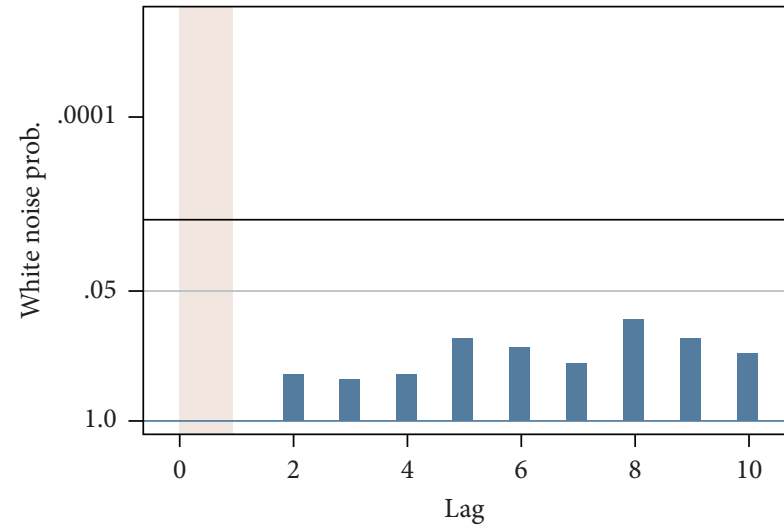

(d)

Figure 3: Autoregressive plots of residual error of LTF model.

TABLE 1: Estimated results of green finance RDL model.

\begin{tabular}{lccccc}
\hline Parameter & Estimate & $\begin{array}{c}\text { Standard } \\
\text { error }\end{array}$ & $\begin{array}{c}T \\
\text { value }\end{array}$ & $\begin{array}{c}\text { Approx- } \\
t<P<t\end{array}$ & Lag \\
\hline MU & 0.0031 & 0.0021 & 1.47 & 0.1409 & 0 \\
MA1,1 & 0.2817 & 0.0919 & 3.06 & 0.0022 & 1 \\
MA1,2 & 0.3593 & 0.0946 & 3.80 & 0.0001 & 2 \\
MA2,1 & -0.1337 & 0.1018 & -1.31 & 0.1891 & 11 \\
NUM1 & 0.0054 & 0.0010 & 5.08 & $<0.001$ & 0 \\
NUM1,1 & -0.0013 & 0.0010 & -1.33 & 0.1823 & 1 \\
\hline
\end{tabular}

TABLE 2: Estimated results of the revised RDL model for green finance.

\begin{tabular}{lccccc}
\hline Parameter & Estimate & $\begin{array}{c}\text { Standard } \\
\text { error }\end{array}$ & $\begin{array}{c}T \\
\text { value }\end{array}$ & $\begin{array}{c}\text { Approx- } \\
t<P<t\end{array}$ & Lag \\
\hline MU & 0.0029 & 0.0018 & 1.67 & 0.0940 & 0 \\
MA1,1 & 0.3028 & 0.0905 & 3.34 & 0.0008 & 0 \\
MA1,2 & 0.3582 & 0.0932 & 3.85 & 0.0001 & 0 \\
NUM1 & -0.0053 & 0.0011 & 4.81 & $<0.001$ & 9 \\
\hline
\end{tabular}

on smart cities, and this impact occurs after 14 months. The model diagnosis results show that there are common variables in the residuals of the RDL model and ARIMA model
TABLE 3: Estimation results of fintech RDL model.

\begin{tabular}{lccccc}
\hline Parameter & Estimate & $\begin{array}{c}\text { Standard } \\
\text { error }\end{array}$ & $\begin{array}{c}T \\
\text { value }\end{array}$ & $\begin{array}{c}\text { Approx- } \\
t<P<t\end{array}$ & Lag \\
\hline MU & 0.0545 & 0.0011 & 1.17 & 0.2503 & 0 \\
AR1,1 & 0.0598 & 0.0987 & -5.06 & 0.0564 & 0 \\
AR2,1 & 0.0569 & 0.0945 & -1.65 & 0.0641 & 0 \\
NUM1 & 0.0065 & 0.0965 & 4.12 & $<0.001$ & 14 \\
NUM2 & 0.0058 & 0.0354 & -1.25 & $<0.001$ & 6 \\
NUM1,1 & 0.0965 & 0.0569 & 0.59 & $<0.001$ & 6 \\
\hline
\end{tabular}

TABLE 4: RDL model estimation results.

\begin{tabular}{lccccc}
\hline Parameter Estimate & $\begin{array}{c}\text { Standard } \\
\text { error }\end{array}$ & $\begin{array}{c}T \\
\text { value }\end{array}$ & $\begin{array}{c}\text { Approx- } \\
t<P<t\end{array}$ & Lag \\
\hline MU & 0.0596 & 0.0023 & 1.19 & 0.2336 & 0 \\
AR1,1 & -0.0632 & 0.0895 & -6.03 & $<0.001$ & 0 \\
NUM1 & 0.0782 & 0.0652 & 2.48 & 0.0130 & 14 \\
\hline
\end{tabular}

constructed in this paper. Due to the influence of common variables, the results of their specific parameter estimation may not be stable. Figure 7 is CCF significance test chart of two residual sequences. 


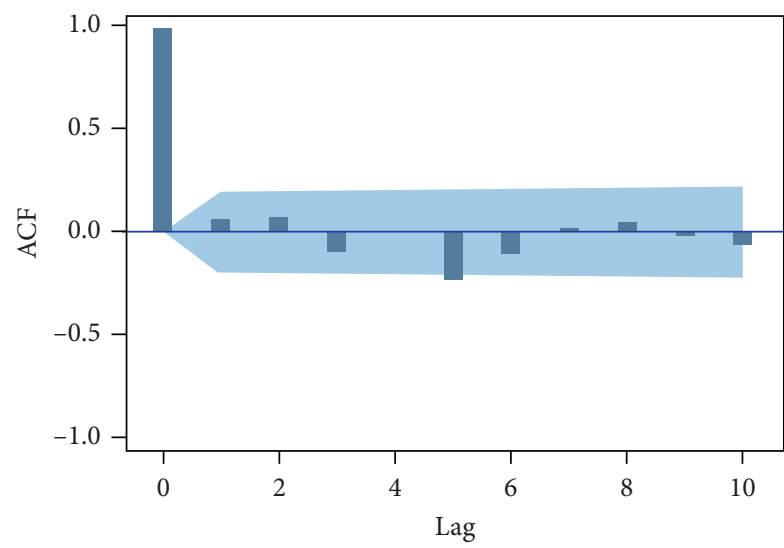

(a)

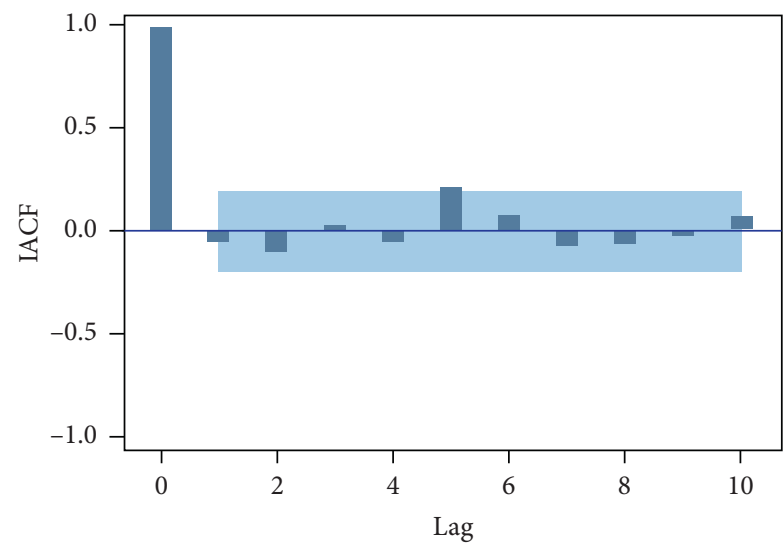

(c)

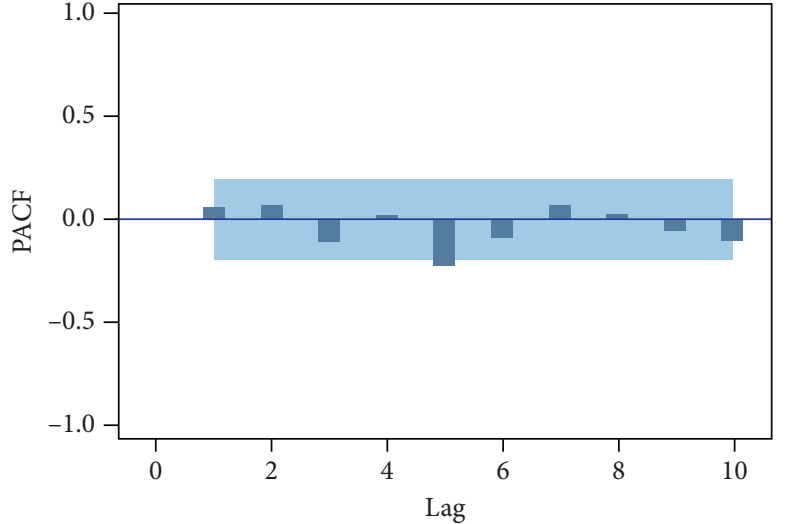

(b)

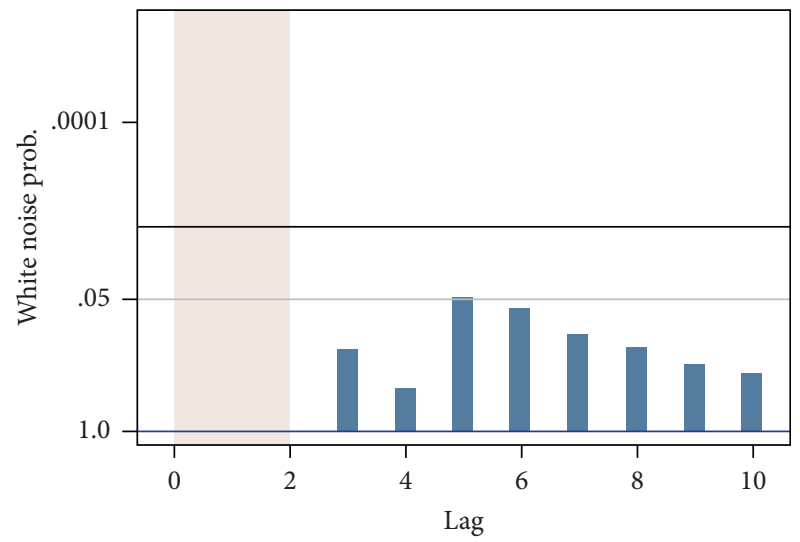

(d)

FIgURE 4: Residual normality test chart of RDL model after green finance correction.

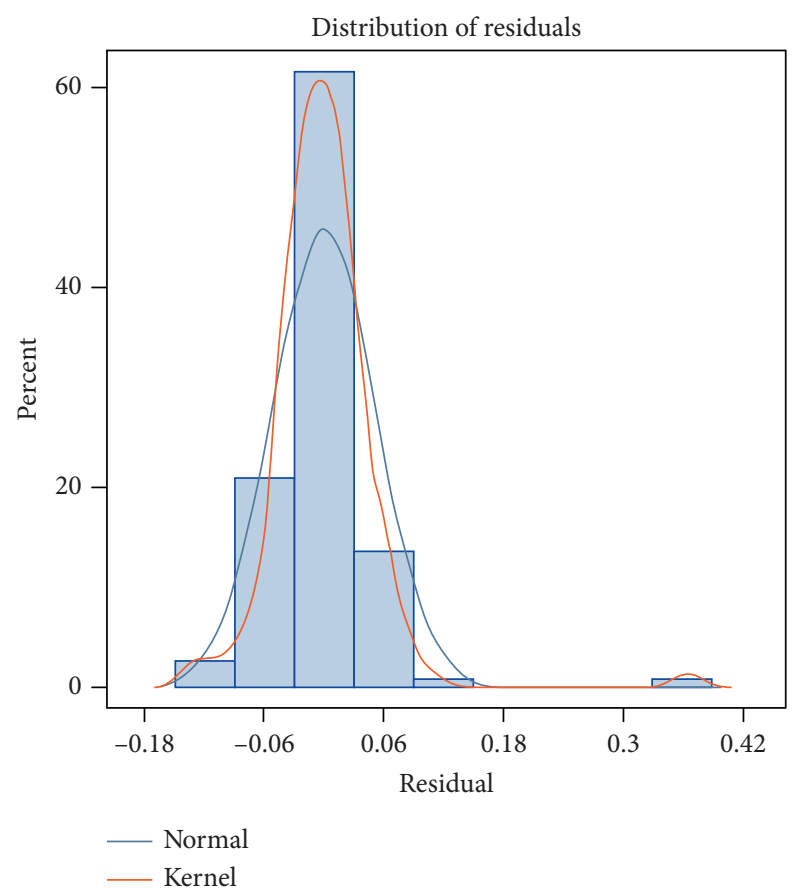

(a)

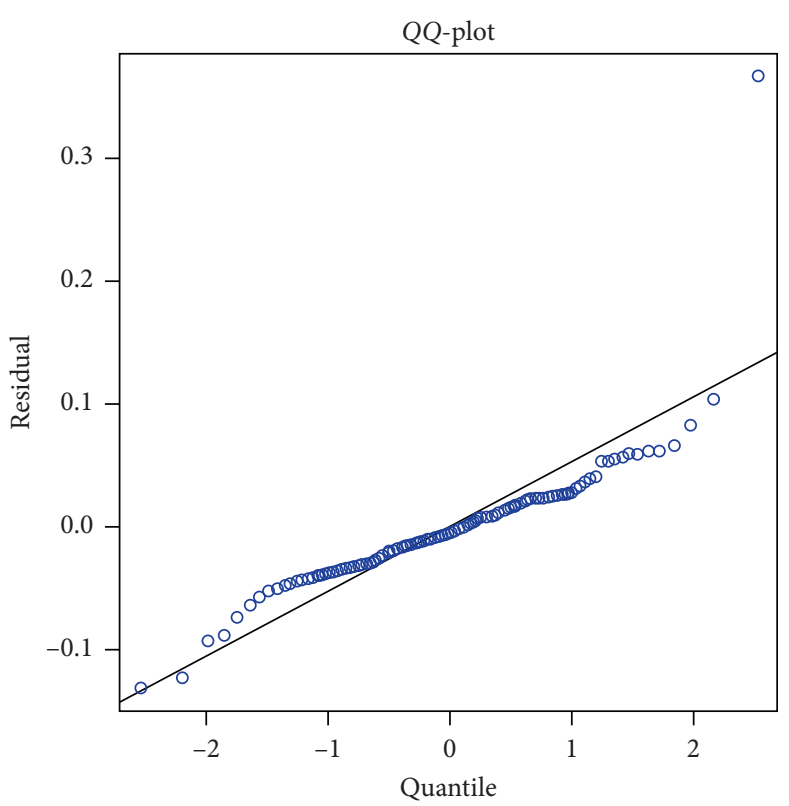

(b)

FIGURE 5: Autocorrelation diagnosis diagrams of the residual error of the RDL model after green finance correction. 
TABle 5: Maximum likelihood estimation results of the fintech ARIMA model.

\begin{tabular}{|c|c|c|c|c|c|}
\hline Parameter & Estimate & Standard error & $T$ value & Approx- $t<P<t$ & Lag \\
\hline MU & -0.0642 & 0.0865 & -0.08 & 0.9358 & 0 \\
\hline AR 1,1 & -0.5653 & 0.0824 & -2.60 & 0.0082 & 1 \\
\hline AR 1,2 & -0.9252 & 0.0963 & -4.26 & $<0.001$ & 2 \\
\hline AR1,3 & -0.4545 & 0.0918 & -6.35 & $<0.001$ & 3 \\
\hline $\mathrm{AR} 1,4$ & -0.2545 & 0.0854 & -2.26 & 0.0235 & 4 \\
\hline AR2,1 & -0.2224 & 0.0871 & -7.21 & $<0.001$ & 11 \\
\hline AR2,2 & -0.7554 & 0.1025 & -4.26 & $<0.001$ & 22 \\
\hline AR2,3 & -0.7893 & 0.0965 & -2.60 & 0.0093 & 33 \\
\hline
\end{tabular}

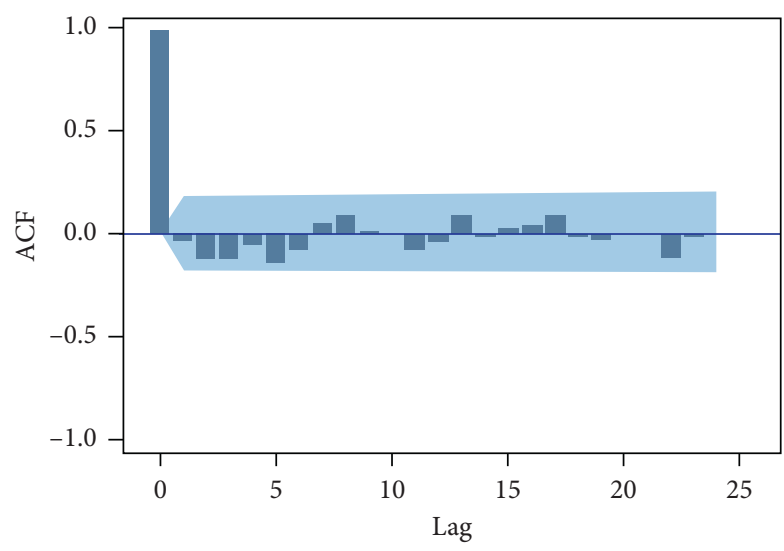

(a)

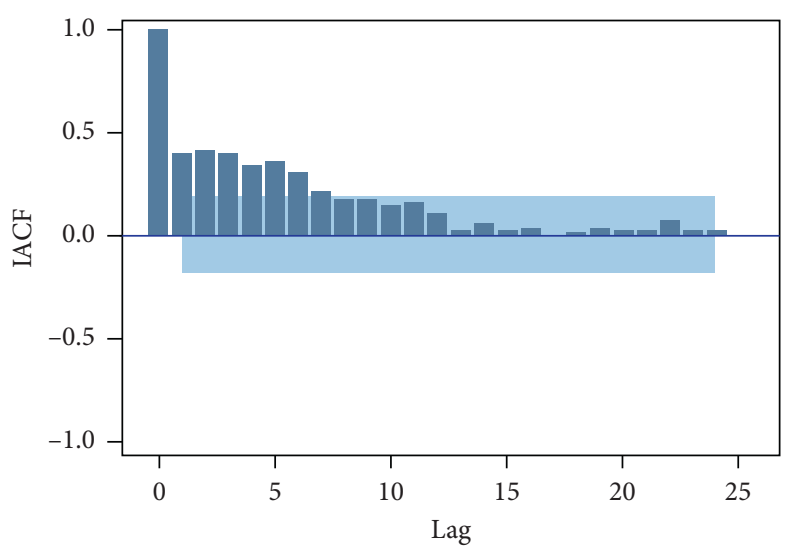

(c)

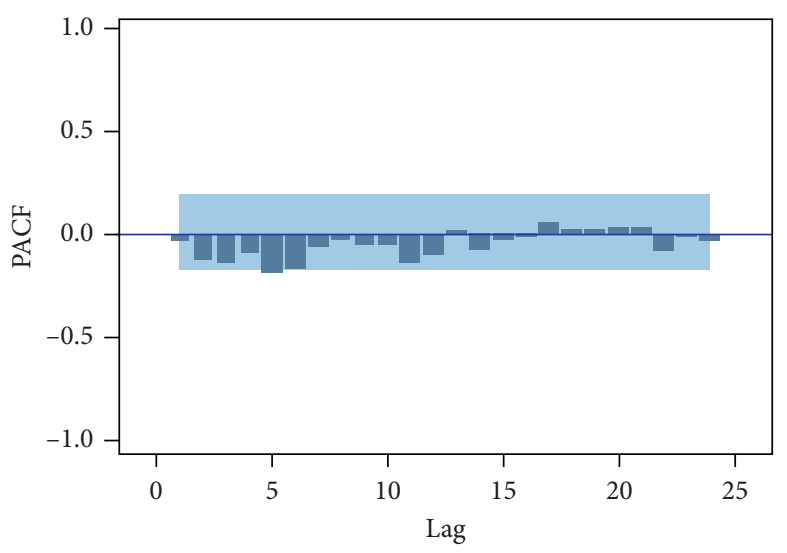

(b)

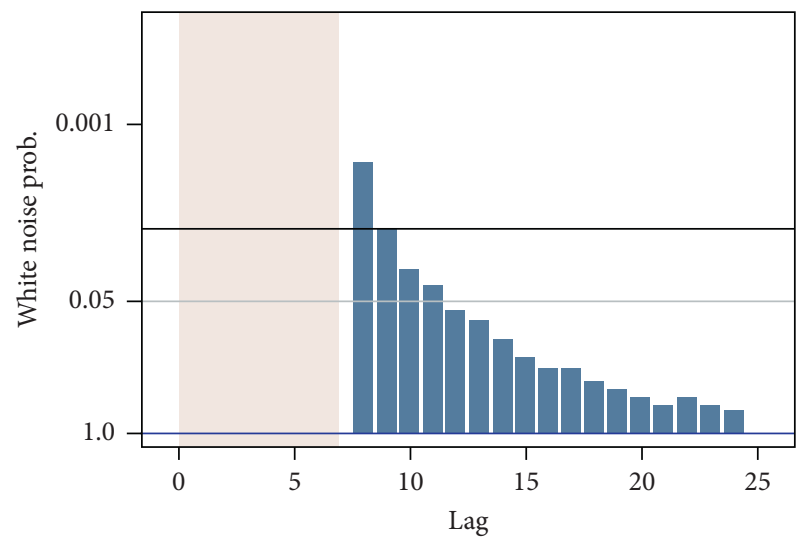

(d)

FIgURe 6: Autocorrelation test chart of fintech ARIMA model residuals.

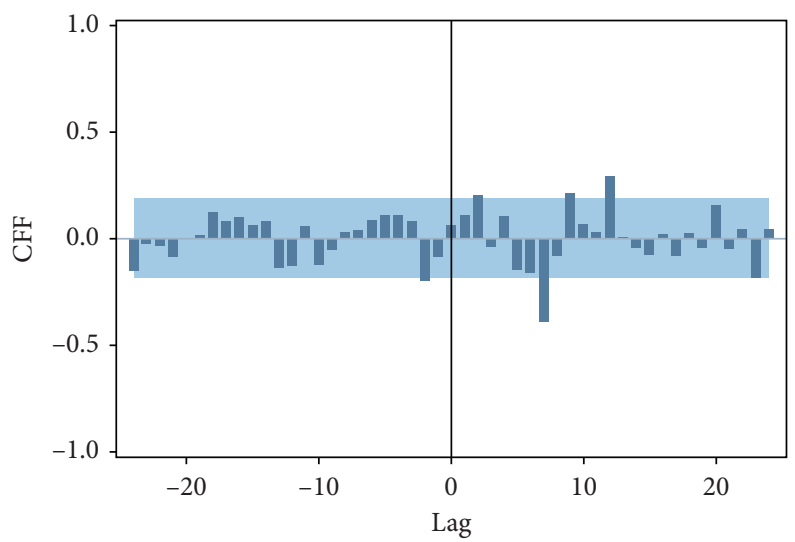

Figure 7: CCF significance test chart of two residual sequences. 


\section{Discussion}

The first is to innovate financial institutions and vigorously develop technology banks, technology microcredit companies, and financial leasing companies. On the premise of following the law of development of technology innovation, expand diversified financing channels, and, at the same time, use mechanism innovation as a driving force to strengthen internal incentives. Improve fair and objective assessment mechanisms and improve protection systems such as risk compensation. The second is to innovate financial products, efficiently use differential risk tolerance to support scientific and technological credit, promote high-yield bond and equity bond financing methods, and comprehensively promote intellectual property pledge financing and repayment. Innovation in financing methods: the third is innovative financing methods, breaking through the traditional service model of indirect financing, financial team and equity, and venture capital investment and loan linkage; the fourth is focusing on the development opportunities of Internet financial technology innovation, fostering "Internet thinking," and actively promoting "networks" "Process" model; creating Internet banking, high-quality service platforms, electronic banking, online revolving loans, and other IT banks; effectively solving the "gap" in funds faced by high-tech projects; promoting the output and diffusion of technological innovation; and promoting the development of information technology in smart cities.

The core of the development of green finance lies in financial intermediaries. The market's actual demand for green finance requires financial institutions to continuously improve their awareness of social responsibility and environmental protection, and carry out targeted green finance promotion and education for internal staff. When making business decisions, we must coordinate the relationship between social responsibility and self-interest. We must always consider environmental protection and sociality in daily operations. Strict environmental protection social responsibility runs through all daily business activities. The financial community must maintain the concept of developing green finance at all times. It must take a dialectical and unified view of the social responsibility and self-realized benefits of enterprises when they conduct green financial business and promote the development of green finance as a long-term strategy to operate, financial institutions. The government should actively carry out green finance publicity work, publicize the government's ideas and measures in developing green finance, and explain the positive changes that green finance development will bring to the lives and work of the general public. On this basis, companies can actively participate in promoting the development of green finance.

One of the major obstacles facing the development of China's green finance is the incomplete information sharing mechanism between different institutions in green finance and the problem of information asymmetry in different sectors, especially the financial and environmental protection sectors that are closely related to green finance. The information asymmetry between the two departments lays hidden dangers for the occurrence of financial risks. Through the application of fintech, a green financial information database can be established between departments, thereby forming a stable communication and coordination mechanism and achieving information sharing between the two parties. At the same time, regulators can also use realtime tracking and monitoring of enterprises participating in green credit through the application of fintech and update related information in real time. In addition, a mature information disclosure system should also be established through the application of fintech, the disclosure procedures for financial institutions to provide green financial services to enterprises, the role of the public and groups in supervision, and the strengthening to cooperate with each other to create a system of vertical supervision and horizontal supervision.

\section{Conclusions}

Starting from the relationship between green finance, fintech, and smart city construction, this study selects data from 2013 to 2019 and uses a distributed lag model to demonstrate it. The following conclusions are obtained: first, green finance promotes smart city construction and green credit. The promotion effect of green financial indicators composed of seven aspects including green bonds, green bonds, green development funds, green insurance, green stocks, green investment, and carbon finance on the construction of smart cities will not appear until nine months later. The honey lake fintech index has verified that it has a reverse effect on the construction of smart cities through models. This is mainly due to the high cost of fintech research, marketization, and profitability, which hinders the construction of smart cities to a certain extent. The effect of this effect will appear after 14 months.

\section{Data Availability}

Some or all data, models, or codes generated or used during the study are available from the corresponding author by request.

\section{Conflicts of Interest}

The authors declare that they have no conflicts of interest.

\section{Acknowledgments}

The funding was sponsored by the National Social Science Fund of China (Grant no. 18CGL015).

\section{References}

[1] M. A. White, "Environmental finance: value and risk in an age of ecology," Business Strategy \& the Environment, vol. 5, no. 3, pp. 198-206, 1996.

[2] A. B. Coulson, "Sustainable banking and finance: people-the financial sector and the future of the planet," Futures, vol. 35, no. 8, pp. 894-895, 2003.

[3] S. Dimitriadis, A. Kouremenos, and N. Kyrezis, "Trust-based segmentation: preliminary evidence from technology-enabled 
bank channels," International Journal of Bank Marketing, vol. 29 , no. 29 , pp. 5-31, 2011.

[4] S. C. Morrish and C. Lee, "Country of origin as a source of sustainable competitive advantage: the case for international higher education institutions in New Zealand," Journal of Strategic Marketing, vol. 19, no. 6, pp. 517-529, 2011.

[5] K. Kaufer, "Social responsibility as a core business model in banking: a case study in the financial sector," Journal of Sustainable Finance \& Investment, vol. 4, no. 1, pp. 76-89, 2014.

[6] N. Apergis, I. Filippidis, and C. Economidou, "Financial deepening and economic growth linkages: a panel data analysis," Review of World Economics, vol. 143, no. 1, pp. 179-198, 2007.

[7] C. Wright, "Global banks, the environment, and human rights: the impact of the equator principles on lending policies and practices," Global Environmental Politics, vol. 12, no. 1, pp. 56-77, 2012.

[8] B. M. S. van Praag, P. Frijters, and A. Ferrer-i-Carbonell, "The anatomy of subjective well-being," Journal of Economic Behavior \& Organization, vol. 51, no. 1, pp. 29-49, 2003.

[9] H. M. Mueller and C. Yannelis, "The rise in student loan defaults," Journal of Financial Economics, vol. 131, no. 1, pp. 1-19, 2019.

[10] N. D. Philippas and C. Avdoulas, "Financial literacy and financial well-being among generation- $Z$ university students: evidence from Greece," The European Journal of Finance, vol. 26, no. 4-5, pp. 360-381, 2020.

[11] M. Shaban, C. Girardone, and A. Sarkisyan, "cross-country variation in financial inclusion: a global perspective," European Journal of Finance, vol. 26, no. 4-5, pp. 319-340, 2020.

[12] M. Swan, "Anticipating the economic benefits of blockchain," Technology Innovation Management Review, vol. 7, no. 10, pp. 6-13, 2017.

[13] M. Swan and P. de Filippi, "Toward a philosophy of blockchain: a symposium: introduction," Metaphilosophy, vol. 48, no. 5, pp. 603-619, 2017.

[14] Y. Yun and M. Lee, "Smart city 4.0 from the perspective of open innovation," Journal of Open Innovation: Technology, Market, and Complexity, vol. 5, no. 4, pp. 92-107, 2019.

[15] R. U. Arora, "Financial sector development and smart cities: the Indian case," Sustainable Cities and Society, vol. 42, pp. 52-58, 2018.

[16] Y. J. Shin and Y. Choi, "Feasibility of the fintech industry as an innovation platform for sustainable economic growth in korea," Sustainability, vol. 11, no. 19, pp. 5351-5372, 2019.

[17] P. Schulte and G. Liu, "FinTech is merging with IoT and AI to challenge banks: how entrenched interests can prepare," The Journal of Alternative Investments, vol. 20, no. 3, pp. 41-57, 2017.

[18] S. Heinemann and M. Kreyling, "Paving the way towards smart cities using AI-digital automotive services research project," ATZelectronics Worldwide, vol. 14, no. 1-2, pp. 54-59, 2019.

[19] W. Sun, Y. Zhao, and L. Sun, "Big data analytics for venture capital application: towards innovation performance improvement," International Journal of Information Management, vol. 50, no. 2, pp. 557-565, 2019.

[20] H. Liang, J. Zou, K. Zuo, and K. Muhammad Junaid, "An improved genetic algorithm optimization fuzzy controller applied to the wellhead back pressure control system," Mechanical Systems and Signal Processing, vol. 142, no. 8, pp. 1-14, 2020.
[21] L. Sun, Y. Zhao, W. Sun, and Z. Liu, "Study on supply chain strategy based on cost income model and multi-access edge computing under the background of the Internet of Things," Neural Computing and Applications, vol. 32, no. 19, pp. 15357-15368, 2020.

[22] Z. Huang, X. Xu, J. Ni, H. Zhu, and C. Wang, "Multimodal representation learning for recommendation in Internet of Things," IEEE Internet of Things Journal, vol. 6, no. 6, pp. 10675-10685, 2019.

[23] H. Liang, J. Zou, Z. Li, M. J. Khan, and Y. Lu, "Dynamic evaluation of drilling leakage risk based on fuzzy theory and PSO-SVR algorithm," Future Generation Computer Systems, vol. 95, no. 6, pp. 454-466, 2019.

[24] M. Xie, H. Li, and Y. Zhao, "Blockchain financial investment based on deep learning network algorithm," Journal of Computational and Applied Mathematics, vol. 372, no. 7, pp. 1-11, 2020.

[25] Z. Liu, B. Hu, B. Huang, L. Lang et al., "Decision optimization of low-carbon dual-channel supply chain of auto parts based on smart city architecture," Complexity, vol. 2020, no. 5, pp. 1-14, 2020.

[26] Y. Zhang, R. Zhu, Z. Chen, J. Gao et al., "Evaluating and selecting features via information theoretic lower bounds of feature inner correlations for high-dimensional data," European Journal of Operational Research, vol. 6, 2020.

[27] H. Liang, A. Xian, M. Min Mao, P. Ni et al., "A research on remote fracturing monitoring and decision-making method supporting smart city," Sustainable Cities and Society, vol. 62, no. 11, pp. 1-11, 2020. 